\title{
Sustained-release quinidine (Kinidin Durules) in maintaining sinus rhythm after electroversion of atrial dysrhythmias
}

\author{
Leon Resnekov, ${ }^{1}$ Derek Gibson, Salvador Waich, ${ }^{2}$ John Muir, and \\ Lawson McDonald ${ }^{3}$ \\ From The National Heart Hospital and Institute of Cardiology, \\ Westmoreland Street, London W.I
}

A trial is reported of sustained-release quinidine bisulphate (Kinidin Durules) controlled by quinidine blood levels used to maintain sinus rhythm after the electroversion of atrial dysrhythmias in 24 patients. Sinus rhythm was brought about by phased direct current shock, neither preceded by nor followed by Kinidin, and all 24 patients relapsed to their original rhythm disturbance, the mean relapse time being 3.75 months after DC shock. A second electroversion preceded and followed by maintenance Kinidin was performed, and the mean electrical energy for conversion to sinus rhythm remained unchanged at 142 joules. The dose of slow-release quinidine was controlled by frequent quinidine blood levels. A careful follow-up study was maintained for 26 months. Trolve patients have remained in sinus rhythm for a significantly longer period while taking Kinidin, in whom the mean quinidine blood level was $2 \cdot 1 \mu \mathrm{g} . / \mathrm{ml}$., eight reverted in a shorter time despite the same mean quinidine blood levels, and in four the length of time of maintained sinus rhythm was unchanged. Complications to the quinidine preparation occurred in four (25\%) and included undue gain in weight, skin sensitivity, gastrointestinal bleeding, and severe diarrhoea. The results of the trial when analysed statistically show a small benefit in the use of this preparation in maintaining sinus rhythm for an additional four months after electroversion, when the optimal dose controlled by frequent blood levels is administered, but thereafter there is little evidence that Kinidin Durules are beneficial long term. It is concluded that Kinidin Durules may be worth while in selected patients in whom the drug is well tolerated, particularly if relapse to atrial fibrillation or flutter has occurred within the first few months after electroversion and in whom sinus rhythm is haemodynamically important.

Synchronized capacitor discharge is more effective than alternating current in treating ventricular dysrhythmias (Lown, Amarasingham, and Neuman, 1962) and more effective than drug therapy in converting supraventricular rhythm disturbances to sinus rhythm (McDonald, Resnekov, and O'Brien, 1964). Though initially considered a benign form of treatment (Lown, 1964; Morris et al., I964), potentially serious complications were soon reported (McDonald and Resnekov,

\footnotetext{
Received 6 May 1970.
}

1 Present address: Department of Medicine (Cardiology), University of Chicago, 950 East 59th Street, Chicago, Illinois 60637.

2 Present address: Hospital Universitario, Ciudad Universitario, Caracas, Venezuela.

${ }^{3}$ Requests for reprints should be addressed to Dr. Lawson McDonald.
1965), and an incidence of 14.5 per cent complications was documented in a consecutive series of 220 patients treated (Resnekov and McDonald, 1967). In addition, the number of patients remaining in sinus rhythm after successful electroversion may be disappointingly small. By $9 \frac{1}{2}$ months after treatment, 50 per cent of 193 patients being followed had reverted to their original dysrhythmia (Resnekov and McDonald, I968), nor did quinidine in a divided total dosage of I.2 g. daily appear helpful in maintaining sinus rhythm in these patients. In this communication we wish to report a study in which a new form of sustained-release quinidine - Kinidin Durule (Sannerstedt, 1960; Sjögren, I959; Sjögren and Fryklöf, I960; Sjögren and Östholm, I96r) was used and controlled by quinidine blood level 
estimations in an attempt to maintain sinus rhythm after electroversion. Each patient acted as his own control.

\section{Patients}

Twenty-four patients were studied, all of whom had initially responded to DC shock but who had then relapsed to their original dysrhythmia. Atrial fibrillation was the presenting rhythm in 18, atrial flutter in 5, and paroxysmal atrial tachycardia in I (Table I). Rheumatic valvar heart disease was present in II, coronary heart disease , in 4 , cardiomyopathy in 2 , congenital heart disease (postoperative atrial septal defect) in $I$, and no underlying heart disease could be detected in 6 .

\section{Method}

Patients were treated with direct current shock as previously described (McDonald et al., I964; Resnekov and McDonald, 1968). Digitalis

- preparations when used were stopped for 24-48 hours before treatment. Patients were brought initially into sinus rhythm by direct current shock which was neither preceded by nor followed by quinidine. All 24 relapsed subsequently to their original dysrhythmia, and a second electroversion

- was performed, but this time direct current shock was preceded and followed by sustained-release

- quinidine, as Kinidin Durules, in a dose of $0.25 \mathrm{~g}$. quinidine bisulphate per $20 \mathrm{~kg}$. body weight twice daily, and the first dose was administered 6 hours before direct current shock. Blood samples were obtained just before the first dose for a control quinidine level, and thereafter every 2 hours

- during the first 12 hours and then 24 hours after the commencement of quinidine treatment. In

- addition, all patients had electrocardiograms and chest radiographs before the shock and one day later. The erythrocyte sedimentation rate and the serum levels of aspartate transaminase and lactic dehydrogenase were measured the day before and the day after electrical treatment; no significant changes from control values were recorded. After the second electroversion, all patients were main-

$\checkmark$ tained on Kinidin Durules and followed at 15 days and at monthly intervals for up to 26 months - after the shock. Blood quinidine levels were obtained at each visit approximately 4 to 6 hours after the last oral dose, and the electrocardiogram and chest radiographs were recorded. Quinidine concentrations were determined both by the method of Hamfelt and Malers (1963) and by the - method of Cramér and Isaksson (1963).

\section{Results}

The effects of a single dose of $0.25 \mathrm{~g}$. Kinidin Durules per $20 \mathrm{~kg}$. body weight in 20 patients is shown in Fig. I. An optimum effect was achieved within 2 hours and therapeutic - plasma levels persisted for about ro hours. The duration of maintained sinus rhythm + after the first and second electroversion is shown in Table 2 as well as the electrical energy settings required. The mean duration
TABLE I Patients

\begin{tabular}{|c|c|c|c|c|}
\hline \multirow{3}{*}{$\frac{\text { Case no. }}{1}$} & \multicolumn{2}{|c|}{ Sex and age (yr.) } & \multirow{3}{*}{$\begin{array}{l}\text { Dysrhythmia } \\
\text { Atrial fibrillation } \\
\text { Atrial fibrillation }\end{array}$} & \multirow{2}{*}{$\begin{array}{l}\text { Underlying heart disease } \\
\text { Coronary heart disease }\end{array}$} \\
\hline & M & 54 & & \\
\hline & $\mathbf{M}$ & 46 & & Cardiomyopathy \\
\hline 3 & $\mathbf{F}$ & 50 & Atrial fibrillation & $\begin{array}{l}\text { Rheumatic heart disease, } \\
\text { mitral Starr-Edwards } \\
\text { prosthesis }\end{array}$ \\
\hline 4 & F & 58 & Atrial fibrillation & Coronary heart disease \\
\hline 5 & $\mathbf{M}$ & 50 & Atrial fibrillation & Coronary heart disease \\
\hline 6 & F & 60 & Atrial flutter & $\begin{array}{l}\text { Rheumatic heart disease, } \\
\text { aortic homograft, mitral } \\
\text { valvotomy }\end{array}$ \\
\hline 7 & $\mathbf{M}$ & 48 & Atrial fibrillation & $\begin{array}{l}\text { Rheumatic heart disease, } \\
\text { aortic homograft, mitral } \\
\text { valvotomy }\end{array}$ \\
\hline 8 & $\mathbf{M}$ & 55 & Atrial fibrillation & Coronary heart disease \\
\hline 9 & $\mathbf{F}$ & 44 & Atrial fibrillation & $\begin{array}{l}\text { Atrial septal defect ostium 2, } \\
\text { postoperative }\end{array}$ \\
\hline 10 & $\mathbf{F}$ & 58 & Atrial fibrillation & $\begin{array}{l}\text { Rheumatic heart disease, } \\
\text { mitral valvotomy }\end{array}$ \\
\hline II & $\mathbf{M}$ & 45 & Atrial fibrillation & Lone \\
\hline 12 & F & 48 & Atrial fibrillation & $\begin{array}{l}\text { Rheumatic heart disease, } \\
\text { mitral valvotomy }\end{array}$ \\
\hline 13 & $\mathbf{F}$ & 55 & Atrial fibrillation & $\begin{array}{l}\text { Rheumatic heart disease, } \\
\text { aortic homograft, mitral } \\
\text { valvotomy }\end{array}$ \\
\hline 14 & $\mathrm{~F}$ & 33 & Atrial tachycardia & Lone \\
\hline 15 & $\mathbf{M}$ & 50 & Atrial flutter & $\begin{array}{l}\text { Rheumatic heart disease, } \\
\text { mitral valvotomy }\end{array}$ \\
\hline 16 & M & 46 & Atrial fibrillation & Cardiomyopathy \\
\hline 17 & $\mathbf{M}$ & 44 & Atrial fibrillation & Lone \\
\hline 18 & $\mathbf{M}$ & 27 & Atrial fibrillation & Lone \\
\hline 19 & $\mathbf{M}$ & 47 & Atrial flutter & $\begin{array}{l}\text { Rheumatic heart disease, } \\
\text { mitral valvotomy }\end{array}$ \\
\hline 20 & $\mathbf{M}$ & 34 & Atrial flutter & Lone \\
\hline $2 \mathbf{I}$ & $\mathbf{M}$ & 47 & Atrial fibrillation & $\begin{array}{l}\text { Rheumatic heart disease, } \\
\text { mitral valvotomy }\end{array}$ \\
\hline 22 & $\mathbf{F}$ & 53 & Atrial fibrillation & $\begin{array}{l}\text { Rheumatic heart disease, } \\
\text { mitral valvotomy }\end{array}$ \\
\hline 23 & $\mathbf{M}$ & 53 & Atrial fibrillation & Lone \\
\hline 24 & $\mathbf{F}$ & 50 & Atrial fibrillation & $\begin{array}{l}\text { Rheumatic heart disease, } \\
\text { mitral valvotomy }\end{array}$ \\
\hline
\end{tabular}

of maintained sinus rhythm without Kinidin was 3.75 months, and this was increased to 7.I4 months when electroversion was undertaken in conjunction with and followed by slow-release Kinidin $(p<0.05)$. The average energy for successful electroversion without Kinidin was 146 joules and with Kinidin I42 joules ( $p$ not statistically significant). In addition, Kinidin Durules had no demonstrable effect on the immediate success rate of the conversion of the dysrhythmia to sinus rhythm nor on the development of transient rhythm disturbances immediately after the direct current shock. Its effect on long-term maintenance of sinus rhythm was as follows. Sinus rhythm continued for a longer period in I2, for a shorter period in 8, and was unchanged in 4 patients, and these results are just statistically significant at the 5 per cent level. No significant difference could be determined between the patients with associated rheumatic heart disease and the non- 
TABIE 2 Results of treatment with Kinidin Durules

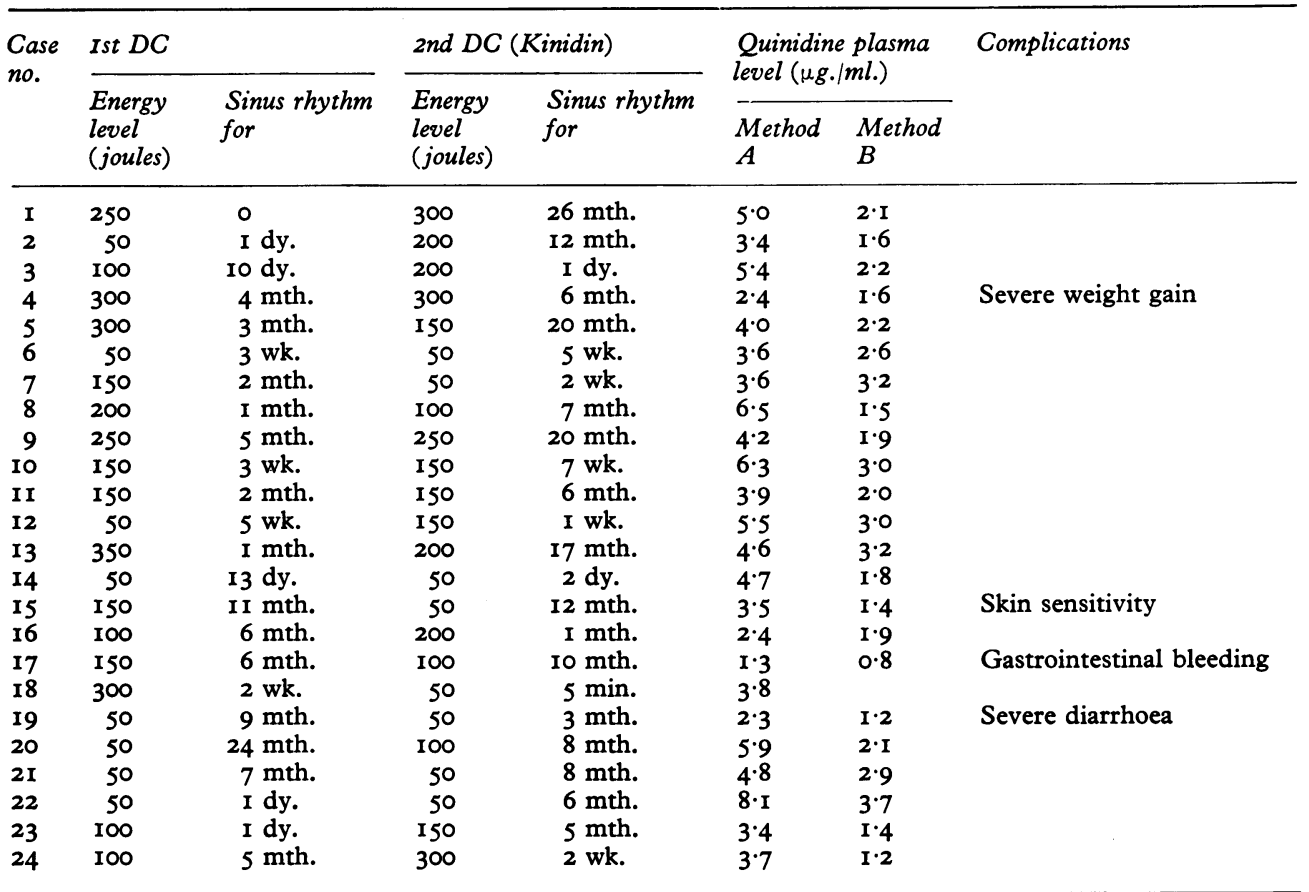

Method A = Precipitation method, Hamfelt and Malers (1963) Same blood sample immediately Method B=Extraction method, Cramér and Isaksson (1963) $\}$ before reversion.

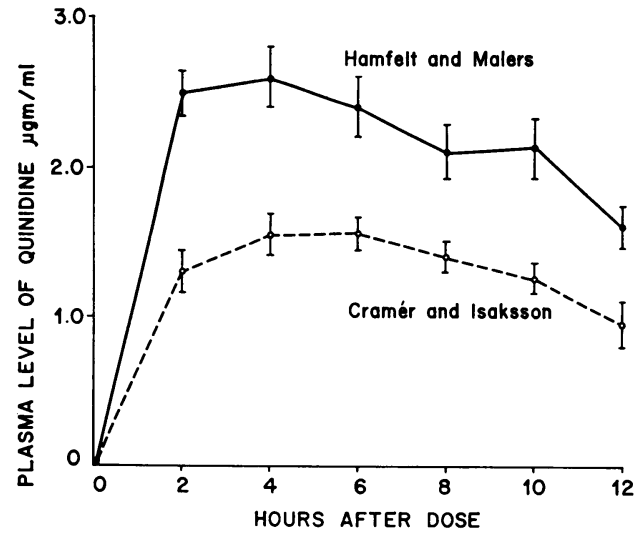

FI G. I Effect of single oral dose Kinidin Durules $0.25 \mathrm{~g} . / 20 \mathrm{~kg}$. body weight. Mean values of plasma quinidine and S.E. of means in 20 patients. Each sample analysed by precipitation method of Hamfelt and Malers (1963) and by the extraction method of Cramér and Isaksson (1963).

rheumatic group. All patients were maintained in the therapeutic range of quinidine blood levels throughout the study ( $\mathrm{I}-4 \mu \mathrm{g} . / \mathrm{ml}$. for the method of Cramér and Isaksson, 3-7 $\mu \mathrm{g}$./ $\mathrm{ml}$. for the method of Hamfelt and Malers), and though peaking of blood quinidine levels was recorded in several patients after a single dose, no patient showed evidence of any cumulative effect developing during longterm administration. Particular attention was paid to the last level of quinidine in the serum or plasma before reversion to the original atrial dysrhythmia occurred (Table 2). All patients who reverted to their dysrhythmia were within the accepted therapeutic range at the time that this occurred. The mean quinidine blood level (method of Cramér and Isaksson) in the 12 patients who maintained sinus rhythm for a longer period of time was $2 \cdot \mathrm{I} \mu \mathrm{g}$. $/ \mathrm{ml}$. and was also $2 \cdot \mathrm{I} \mu \mathrm{g}$. $/ \mathrm{ml}$. for the 8 patients in whom sinus rhythm persisted for a shorter time. Electrocardiograms were carefully analysed throughout the study and showed prolongation of the QT interval while taking Kinidin; the most obvious change occurred in those patients in whom the blood quinidine level was highest. Complications developed in four patients while taking Kinidin and included rapid gain in weight, skin sensitivity, gastrointestinal bleeding, and diarrhoea (Table 2). Though gain in weight is an unusual complication, it responded dramatically to stopping the Kinidin in our patient. Treatment had to be discontinued in Case 19 
because of severe diarrhoea which could not be controlled and in Case 15 because of a severe skin sensitivity reaction. There was no clinical evidence of worsening of the cardiac status of the patient between the first and second electroversion.

\section{Discussion}

Direct current shock has become established as the treatment of choice for acute atrial and ventricular rhythm disturbances. The success of treatment, however, may be considered - under two main headings. (I) Immediate success, and (2) long-term maintenance of sinus rhythm. When a uniform stage of depolarization of the myocardial fibres is brought about by direct current shock, the entire heart becomes refractory and impulse propagation is abolished. The energy used - must be sufficient to depolarize simultaneously as many of the myocardial fibres as possible. In addition, successful direct current shock requires that the sino-atrial node is neither diseased nor atrophied and is capable of reintroducing sinus rhythm. Furthermore, it is - also important that the likelihood of a recur- rence of the original dysrhythmia is prevented so far as possible when sinus rhythm has been achieved by electrical depolarization. Rhythm disturbances immediately after DC shock are related in part to the release of catecholamine by myocardial nerve fibres and the amount - released is directly related to the electrical energy employed. Frequent atrial and ventricular extrasystoles are often seen immediately after DC shock, and when present may potentiate new or recurrent atrial or ventricular dysrhythmias. Digitalis overdosage may be responsible for failure to bring about sinus rhythm, but, more important, it may precipitate serious disturbances of ventricular rhythm after the shock (Resnekov, 1965). In addition, parasympathetic and sympathetic

-mediators released at the time of DC shock may be important in an abrupt return of the initial rhythm disturbance (Childers, Rothbaum, and Arnsdorf, 1967).

Quinidine therapy has been considered the -treatment of choice for maintaining sinus rhythm in patients with chronic atrial fibrillation after successful DC shock (Lown, Kleiger, and Wolff, 1964). Rossi and Lown (1967), who studied roo patients, 50 of whom were maintained on oral quinidine sulphate I.2 g. daily, reported that not only did \&quinidine improve the chances of remaining in sinus rhythm, but it also reduced the selectrical energy and number of shocks required; the incidence of serious postelectroversion rhythm disturbances was re- duced. Toxic effects of intermittent oral quinidine sulphate have been documented (McDonald et al., 1964), some of which have been extremely serious, including ventricular fibrillation in 3 out of 50 patients. Selzer and Wray (1964) have suggested that these serious rhythm disturbances may be related to rapid changes in blood quinidine levels.

Kinidin Durules are tablets of quinidine bisulphate in which the active drug is embedded in a porous insoluble plastic tablet. It releases 40 per cent of the dose in the first hour and the remainder is steadily released over the next 8 hours. Quinidine is probably not absorbed in the stomach, but is rapidly absorbed in the alkaline medium of the small intestine. Using Kinidin Durules, the maximum concentration achieved is significantly lower and the peak quinidine concentration seen after the ordinary form of quinidine bisulphate is replaced by a plateau which develops gradually and then falls off (Fig. I). The absence of fluctuations of concentration indicate that the release is regular and also reliable in respect to different patients. The elimination of Kinidin appears to be similar to the elimination of quinidine sulphate. Therapeutically effective levels of plasma or serum concentration, however, can be easily achieved using this new preparation and can be maintained for a prolonged period of time. In our series, the maximum concentration appeared 2 to 4 hours after the initial dose (Fig. I), and there was little difficulty in maintaining patients in the therapeutic range.

It is important to consider the method of quinidine estimation. Two methods are commonly used, namely that of Cramér and Isaksson (1963), and that of Hamfelt and Malers (1963). Throughout the trial, both were used and compared. The method of Cramér and Isaksson is an extraction one based on the methods proposed by Brodie, Udenfriend, and Baer (1947a) and by Brodie et al. (1947b) in which quinidine is measured with very little metabolite adherence. In contrast, with the precipitation method of Hamfelt and Malers based on the older method of Brodie and Udenfriend (1943), quinidine and its metabolites, not all of which have antidysrhythmic activity, are measured by a fluorometric determination after protein precipitation. It has been shown that the extraction method of Cramér and Isaksson is superior to the precipitation method, and furthermore that extraction by benzene is preferable to ethylene dichloride extraction as proposed by Edgar and Sokolow (I950). With the extraction method, nearly 100 per cent of pure quinidine added to plasma may 


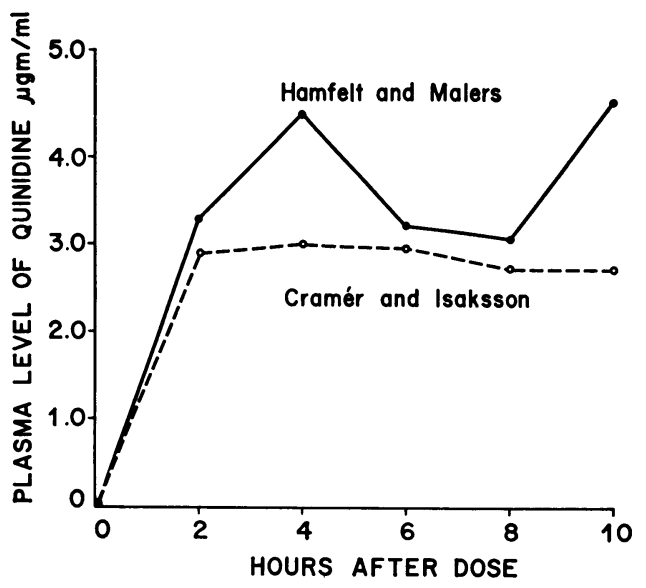

FIG. 2 Quinidine plasma levels after a single oral dose Kinidin Durules $0.25 \mathrm{~g} . / 20 \mathrm{~kg}$. body weight in Case 10. Blood samples analysed by the precipitation method (Hamfelt and Malers) and by the extraction method (Cramér and Isaksson). See text.

be recovered and the error of a single determination is I per cent (Cramér and Isaksson, 1963). While the methods of Cramér and Isaksson and of Hamfelt and Malers were used throughout the trial, a comparison of the results obtained on the same samples of blood after a single dose of Kinidin Durules in one patient is shown in Fig. 2, and the extraction method of Cramér and Isaksson is preferred in clinical use. There seems little difference whether plasma or serum is analysed, and our studies were undertaken using heparinized blood samples and the results expressed as $\mu \mathrm{g} . / \mathrm{ml}$. of plasma. After separation of the plasma, samples may be left refrigerated for up to 7 days before being analysed, but haemolysis must be avoided or the samples will be unfit for analysis.

Despite the absence of peaking of serum quinidine levels, the incidence of complications in our series was disappointingly high, and as already described the drug had to be stopped in two patients because of uncontrollable symptoms.

The factors important in maintaining sinus rhythm are the length of time the dysrhythmia has been present before treatment, the overall size of the heart, the size of the left atrium, the underlying heart condition, and the integrity of the sinus mechanism (Resnekov, 1965), and slow-release quinidine sulphate does not appear to be beneficial when any or all of these are unfavourable. In contrast to the re- sults published by Sokolow and Perloff (19606I), our results were not influenced by the underlying heart condition, though as can be seen from Table I, the majority of our patients had suffered rheumatic heart disease. It has been suggested that quinidine in divided doses may be helpful in maintaining sinus rhythm in the immediate post-conversion period (Morris et al., 1964; Rossi and Lown, 1967), and Härtel et al. (1970) have shown that Kinidin Durules are effective up to three months after electroversion. Our results have failed to indicate a clear-cut benefit when Kinidin Durules are used to maintain sinus rhythm long-term, though the average duration of maintained sinus rhythm was increased from 3.75 months to 7.14 months. Our results confirm those of Hall and Wood (1968) that quinidine is disappointing in maintaining sinus rhythm long term in patients treated for chronic atrial fibrillation, even when we have used a sustained action quinidine tablet controlled by blood quinidine levels. Though we have shown a pharmacological effect of the drug in maintaining sinus rhythm for an additional four months, we feel that its routine use is not clinically indicated in view of the possible complications of the drug. It may be worth while in selected patients in whom the drug is well tolerated, particularly if relapse to atrial fibrillation or flutter has occurred within the first few months after electroversion and in whom sinus rhythm is haemodynamically important.

\section{References}

Brodie, B. B., and Udenfriend, S. (1943). The estimation of quinine in human plasma with a note on the estimation of quinidine. Fournal of Pharmacology and Experimental Therapeutics, 78, 154.

$\longrightarrow$ - and Baer, J. E. (1947a). The estimation of basic organic compounds in biological material. $\mathbf{r}$. General principles. Fournal of Biological Chemistry, 168, 299.

$\longrightarrow,-$ Dill, W., and Downing, G. (1947b). The estimation of basic organic compounds in biological material. II. Estimation of fluorescent compounds. Fournal of Biological Chemistry, 168, $31 \mathrm{I}$.

Childers, R. W., Rothbaum, D., and Arnsdorf, M. F. (1967). Effect of direct-current shock on the electrical properties of the heart. Circulation, 36, Suppl. 2, 85 .

Cramér, G., and Isaksson, B. (1963). Quantitative determination of quinidine in plasma. Scandinavian Fournal of Clinical and Laboratory Investigation, 15,

Edgar, A. L., and Sokolow, M. (1950). Experiences with the photofluorometric determination of quinidine in blood. Fournal of Laboratory and Clinical Medicine, 36, 478.

Hall, J. I., and Wood, D. R. (1968). Factors affecting cardioversion of atrial arrhythmias with special reference to quinidine. British Heart fournal, 30, 84. 
Hamfelt, A., and Malers, E. (1963). Determination of quinidine concentration in serum in the control of quinidine therapy. Acta Societatis Medicorum Upsaliensis, 68, 181.

Härtel, G., Louhija, A., Konttinen, A., and Halonen, P. I. (I970). Value of quinidine in maintenance of sinus rhythm after electric conversion of atrial fibrillation. British Heart fournal, 32, 57.

Lown, B. (1964). 'Cardioversion' of arrhythmias, II. Modern Concepts of Cardiovascular Disease, 33, 863.

- Amarasingham, R., and Neuman, J. (I962). New method for terminating cardiac arrhythmias. Use of synchronized capacitor discharge. Fournal of the American Medical Association, 182, 548.

-, Kleiger, R., and Wolff, G. (1964). The technique of cardioversion. American Heart fournal, 67, 282.

McDonald, L., and Resenekov, L. (1965). Atrial defibrillation. In Resuscitation and Cardiac Pacing, p. 140. Ed. by G. Shaw, G. Smith, and T. J. Thomson. Cassell, London.

—_, O'Brien, K. (1964). Direct-current shock in treatment of drug-resistant cardiac arrhythmias. British Medical fournal, 1, 1468.

Morris, J. J., Jr., Kong, Y., North, W. C., and McIntosh, H. D. (1964). Experience with 'cardioversion' of atrial fibrillation and flutter. American fournal of Cardiology, 14, 94.

Resnekov, L. (1965). Synchronised capacitor discharge in the management of cardiac arrhythmias with particular reference to the haemodynamic signifi- cance of atrial systole. M.D. Thesis, University of Cape Town.

- , and McDonald, L. (1967). Complications in 220 patients with cardiac dysrhythmias treated by phased direct current shock, and indications for electroconversion. British Heart fournal, 29, 926.

- and - (1968). Appraisal of electroconversion in treatment of cardiac dysrhythmias. British Heart Fournal, 30, 786.

Rossi, M., and Lown, B. (1967). The use of quinidine in cardioversion. American fournal of Cardiology, 19, 234.

Sannerstedt, R. (1960). Clinical and experimental investigation of a new type of oral prolonged-action tablet (Duretter). Acta Medica Scandinavica, 167, 245.

Selzer, A., and Wray, H. W. (1964). Quinidine syncope. Paroxysmal ventricular fibrillation occurring during treatment of chronic atrial arrhythmias. Circulation, 30, 17.

Sjögren, J. (1959). Sustained action preparations for oral use. Farmacevtisk Revy, 58, 233, 255.

-, and Fryklöf, L. E. (1960). Duretter - a new type of oral sustained action preparation. Farmacevtisk Revy, 59, 17 r.

, and Ostholm, L. (196I). Absorption studies with a sustained release tablet. Fournal of Pharmacy and Pharmacology, 13, 496.

Sokolow, M., and Perloff, O. B. (1960-6I). The clinical pharmacology and use of quinidine in heart disease. Progress in Cardiovascular Disease, 3, 316. 